See discussions, stats, and author profiles for this publication at: https://www.researchgate.net/publication/323322900

\title{
Incorporating Woodwork Fabrication into the Integrated Teaching and Learning of Civil Engineering Students
}

Article in Journal of Professional Issues in Engineering - ASCE · February 2018 DOI: 10.1061/(ASCE)El.1943-5541.0000377

\section{CITATIONS}

5 authors, including:

Bo Li

Wenzhou University

30 PUBLICATIONS 145 CITATIONS

SEE PROFILE

-

Dariusz Wanatowski

University of Leeds

154 PUBLICATIONS 1,350 CITATIONS

SEE PROFILE
156

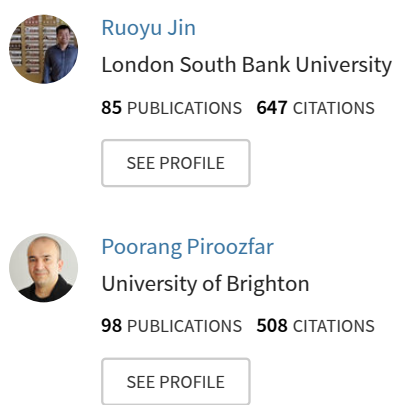

Some of the authors of this publication are also working on these related projects:

Design block week as an effective learning environment for students on Architectural Technology courses View project

Shakedown analysis of pavements View project 
1 Incorporating Woodwork Fabrication into the Integrated Teaching and

2 Learning of Civil Engineering Students

3 Bo Li ${ }^{1}$, Maoyu Zhang ${ }^{2}$, Ruoyu $\mathrm{Jin}^{3}$, Dariusz Wanatowski ${ }^{4}$, M.ASCE, Poorang Piroozfar ${ }^{5}$

\section{Abstract}

5 As an alternative to the traditional structural analysis adopting computer-aided modeling and

6 evaluation, this pedagogical research provided an integrated teaching and learning approach

7 by mapping cognitive domains defined in Bloom's Taxonomy Theory in the newly launched course named Woodwork Fabrication and Analysis for second-year students. The course incorporated ancient Chinese woodwork tradition into the integrated learning activities involving engineering graphics, mechanics of materials, hands-on fabrication, and structural modeling/analysis. Aiming to compare the traditional and new courses in terms of their effectiveness in enhancing student learning of structural engineering subjects, both courses were designed to achieve consistent learning outcomes (e.g., to develop structural analysis skills). This study demonstrated student work in engineering drawing and structural analysis reflecting their critical thinking and active learning in the new course. Afterwards, students from both traditional and new courses were surveyed in terms of the overall satisfaction of their selected course, perceptions of the course effectiveness in enhancing civil engineeringrelated skills, and expectations of the course to their further study and work. With the student

\footnotetext{
${ }^{1}$ Associate Professor, Oujiang College, School of Civil Engineering, Wenzhou University, 301 No. 5 BLDG, North Campus, 325000, Wenzhou, China. Email: libo@wzu.edu.cn

${ }^{2}$ Associate Professor, Oujiang College, School of Civil Engineering, Wenzhou University, 301 No. 5 BLDG, North Campus, 325000, Wenzhou, China. Email: zmy0577@wzu.edu.cn

${ }^{3}$ Senior Lecturer, School of Environment and Technology, University of Brighton, Cockcroft Building 616, BN2 4GJ, Brighton, UK. Email: R.Jin@Brighton.ac.uk

${ }^{4}$ Professor and Pro-Dean of the SWJTU-Leeds Joint School, School of Civil Engineering, Faculty of Engineering, University of Leeds, LS2 9JT, Leeds, United Kingdom. Email: d.wan@leeds.ac.uk

${ }^{5}$ Principal Lecturer, School of Environment and Technology, University of Brighton, Cockcroft Building 630, BN2 4GJ, Brighton, UK. Email: A.E.Piroozfar@Brighton.ac.uk
} 
sample from the traditional course as the control group, the comparative study revealed that the integrated teaching and learning approach in the new course could lead to students' higher overall satisfaction and more positive perceptions of the course effectiveness in enhancing structural analysis-related skills. This pedagogical study would serve as a reference for other civil engineering educators in adopting integrated teaching and learning in lower-years' undergraduate education.

CE Database subject headings:

Author Keywords: Engineering education; Civil engineering pedagogy; engineering graphics; Mechanics of materials; Structural modeling; Structural analysis; Integrated teaching and learning

Introduction

China's annual civil engineering (CE) college graduates have numbered between 80,000 and 85,000 (China Education On-Line, 2014), more than four times of the figure in the U.S., which is around 20,000 (DataUSA, 2015). Despite of the large number of CE graduates in China, there have not been sufficient pedagogical studies to address certain key issues of CE education, specifically, 1) how could CE undergraduates learn and practice in a more effective way whereas Chinese universities are investing more on research facilities with relatively fewer resources for and less focus on teaching and learning? 2) how could Chinese universities have a more integrated curriculum instead of the typical scenario with lower years' CE education focusing on students' knowing and understanding-oriented learning and then moving towards more application and analysis based learning in upper years? 3) how could students be motivated in a more active learning environment (e.g., the experimental approach introduced by Chacón and Oller (2017) in structural subjects) by adopting various teaching and learning activities to achieve a more comprehensive coverage of learning outcomes? 
To address the aforementioned pedagogical gaps, the CE Department at Wenzhou

University in China has implemented the curriculum review and update since early 2016 with the goal of enhancing students' learning experience through integrated teaching and learning methods. A lifelong learning and systematic training in the CE field, stressed by Kubečková (2014), Bussey et al. (2017) and Phillips (2017), is also emphasized in the updated CE curriculum at Wenzhou University. The course of Woodwork Fabrication and Analysis (WFA), was initiated in spring 2016 as the alternative to the traditional course of Computeraided Structural Analysis (CASA). The new WFA course was designed to apply students' knowledge in engineering graphics and mechanics of materials and to develop students' skills in drawing, hands-on fabrication, structural modeling and analysis in an integrated approach.

It differed from many traditional courses in China's CE education in that: 1) it was built upon the pedagogical study of Mackechnie and Buchanan (2012), and Sánchez and Millán (2013) by incorporating hands-on activities in structural analysis; 2) it consisted of teaching activities by adopting Bloom's Taxonomy Theory initiated by Bloom (1956). The WFA and effectiveness and overall satisfaction from the $W F A$ course were evaluated by comparing the feedback of students from the two courses, with the student sample from the CASA course as the control group.

This pedagogical study started from demonstrating student work in the WFA course in engineering drawing, hands-on fabrication, and structural modeling/analysis aiming to reflect their critical thinking and active learning. The main objectives of this pedagogical study are as follows: 1) testing the hypothesis that the two student samples in $W F A$ and $C A S A$ courses had consistent previous academic performance in the CE curriculum and similar motivation levels in structural analysis subjects; and 2) analyzing WFA students' feedback in their learning satisfaction, course effectiveness in enhancing key skills, and effects of this course 
69 in their subsequent years of study and future careers, based on the comparison to the other student sample from the $C A S A$ course. A certain teaching methodology in engineering education could serve as a reference and stimulate other educators (Soria et al., 2013). This pedagogical case would serve as such a reference to other $\mathrm{CE}$ programs in higher education on how the integrated teaching and learning activities could be embraced as updates to traditional CE education. Lessons learned from this new course provide insights of how the innovative integrated teaching and learning activities in lower years of undergraduate $\mathrm{CE}$ curriculum could work as alternatives to traditional computer-aided structural analysis subjects by applying students' knowledge in prior learning meanwhile motivating students' study in follow-up years.

\section{Background}

The integrated pedagogical approach, involving multiple learning activities such as information search, teamwork, research-driven teaching, sustainability, student presentation, and industry-led education, has been applied in some existing CE pedagogies (e.g., Sacks and Barak, 2010; Amekudzi, et al., 2010; Beiler and Evans, 2015; Jainudin et al., 2015; Gadhamshetty et al., 2016; Jin et al., 2018). Some of these pedagogical studies adopted hands-on activities as teaching innovations aiming to enhance the teaching and learning effectiveness, such as those in geotechnical engineering (Cerato et al., 2012), in earthquake engineering (Mosalan et al., 2013), and in structural analysis (Sánchez and Millán, 2013). It is believed by many researchers (e.g., Dancz et al., 2018) including authors of this pedagogical study that traditional hands-on learning activities are one of the most effective teaching methods in $\mathrm{CE}$ education. Information technology applications (such as Building Information Modeling or BIM) in CE and built environment subjects have been undergoing rapid development since 2010, as reported by Sacks and Barak (2010), Tang et al. (2015), Jin et al. (2016), Lucas (2016), and Jin et al. (2018). However, the fast-growing BIM usage does 
94 not mean that it is necessarily the only effective learning tool in CE education. Hands-on learning could complement information technology (e.g., BIM) as another effective learning approach. These multiple teaching and learning activities can be embedded to assess student performance in different levels corresponding to cognitive domains following Bloom's Taxonomy Theory.

Bloom (1956) defined six hierarchy levels of cognitive domain in the Taxonomy Theory, namely knowledge, comprehension, application, analysis, synthesis, and evaluation. Anderson and Krathwohl (2001) further revised the taxonomy, which from lower to higher levels, included remembering, understanding, applying, analyzing, evaluating, and creating. Multiple assessment techniques, believed by Sharma et al. (2017) to provide a means for gaining deeper understanding of student perceptions and learning, could be adopted to address these multiple levels of cognitive domains. Teaching activities that involve application, analysis, synthesis, and evaluation could encourage students' critical thinking. Active learning was identified by multiple researchers (e.g., Youngblood and Beitz, 2001; Walker, 2003; Burbach et al., 2004) as a key approach to develop students' critical thinking. Meyers and Jones (1993) suggested a few effective strategies in promoting active learning in college classroom, including informal group work, simulation, and case studies, etc. These strategies have also been adopted in some previous pedagogical studies in CE, for instance, simulation-based learning in Mosalam et al. (2013), and case studies in Lewis et al. (2014) and Mostafavi et al. (2016). These different teaching and learning strategies would create varied learning environment and students' learning approach (e.g., deep learning and surface learning), which are correlated to their study success as found out by Salmisto et al. (2017).

Besides these teaching strategies adopted in single courses, progressive integration in the CE curriculum can lead to students' continuous improvement in their problem-solving abilities towards project-based tasks (Jackson and Tarhini, 2016). According to Jackson and 
119 Tarhini (2016), the pedagogical approach (i.e., problem-solving framework) could be 120 expanded from freshmen year to upper-level CE courses. Therefore, an individual course could be properly embedded into the existing CE curriculum by applying students' knowledge and skills obtained from prerequisites and by offering the framework or platform (e.g., project-based design) for students' follow-up studies.

\section{Methodology}

The methodology of this pedagogical study can be described in terms of pedagogical research design, course delivery, and follow-up evaluation of student feedback.

\section{Pedagogical research design}

The semi-optional new course of Woodwork Fabrication and Analysis (WFA) was designed for students to apply their prerequisites in engineering graphics and mechanics of materials in an integrated learning approach by combining hand-drawing, hands-on fabrication of woodwork, and structural modeling and analysis assisted by computer software applications. This new course was defined as semi-optional because sophomore CE students had to be enrolled either in it or the other traditional course entitled Computer-aided Structural Analysis (CASA). These two parallel courses shared the consistent learning outcomes (LOs): 1) to enhance skills in engineering graphics, 3D modeling, and spatial reasoning; 2) to enhance the understanding of mechanics; and 3) to obtain the understanding of local force distribution within different structural forms or structural elements. Both $W F A$ and CASA required students to concurrently learn and adopt SAP2000 developed by Computers \& Structures, Inc. (2017) as the structural modeling and analysis tool. Before deciding which semi-optional course to select, students were made aware of the consistent LOs and the same analysis tool between the two courses. The two courses differed in that WFA highlighted the hands-on fabrication leading to a further structural analysis of woodwork. In comparison, $C A S A$ did not include any hands-on fabrication of woodwork. 
Instead, students in the $C A S A$ course were involved in design, and structural analysis of a residential building. In this pedagogical study, students enrolled in the $C A S A$ course would be treated as the control group. Their perceptions towards achievements of LOs upon finishing the course would be compared with their peers enrolled in $W F A$ course.

\section{Course delivery of WFA}

Fig.1 displays how the WFA course was designed and mapped against Bloom's Taxonomy Theory and the theory updated by Anderson and Krathwohl (2001).

According to Fig.1, the $W F A$ course was designed with learning activities mapped from lower level domains (e.g., knowledge and comprehension of wood tangential and radial sections) to higher levels (e.g., evaluation of structural analysis results), except the highest level (i.e, creating) defined by Anderson and Krathwohl (2001). Nevertheless, creatingrelated activities were planned in the follow-up new course in BIM after students finish the current course. Therefore, this course was designed to connect both prerequisites and future courses for CE students in their fourth semester of study. The course consisted of modules in terms of: 1) applying engineering graphics to produce individual drawings of Kong-Ming lock (KML) and four-legged octagonal stool (FLOS) (shown in Fig.2); 2) fabrication of woodwork; and 3) computer-based structural modeling and structural analysis of the fabricated FLOS.

The rationale of adopting KML and FLOS as the woodwork case studies was mainly to introduce the ancient Chinese craftsmanship culture, aesthetics, and traditional artworks into civil engineering education. KML was invented around 2,000 years ago in China's historical period of Triple-Kingdom. It has been widely used as a toy for leisure and entertainment in China. Although KML appears simple, it could be challenging to fabricate or assemble and it is believed to be effective in enhancing the visual spatial intelligence of trainees. FLOS is a classic woodwork in China. Although seemingly simple in its structure, it has all cutting 
surfaces sloped and could be challenging for spatial reasoning. FLOS is considered suitable to enhance student skills in spatial reasoning and geometric modeling. FLOS also requires high accuracy in the fabrication process. It has superior capacity in resisting compressive pressure and was thus adopted as the case study for structural analysis. The WFA course structure and delivery are summarized in Table 1.

It can be seen from Table 1 that the WFA course consisted of formal lectures, laboratory tutorials followed by students' exploratory learning, and working on assignment. The lecture session focused on fabrication and structural theories. It was provided by the faculty to introduce topics related to woodwork fabrication, structural modeling, and analysis. The tutorial session focused on the practical instruction. For example, videos of detailed woodwork fabrication processes were shown to students in workshops. Laboratory technicians and teaching assistants also described detailed methods and processes of handson fabrication to students. The tutorial in structural analysis using software tools was provided in the computer laboratory. It was common practice that lectures were followed by tutorials. Explorative learning was provided to students in the modules of woodwork fabrication and structural analysis. Students were trained to be familiar with fabrication tools and structural modeling, analysis, and evaluation in the exploratory learning hours. Exploratory learning aimed to motivate students' creativity by letting students explore different ways of fabricating woodwork under the supervision of faculty, technician, or teaching assistants. Students were encouraged to develop their ideas in the exploratory learning hours. For example, they could explore alternative design and production approach in tenon structures. The ideas developed during exploratory learning could be adopted in their final submission of project assignment, and ultimately reflected in their grades.

A combination of lecture and follow-up laboratory session consisting of tutorial and exploratory learning was the more common delivery method within a typical class period. 
194 Each class generally lasted for three hours, consisting of lecture and laboratory sessions.

195 Generally the lecture would take a shorter period of time than the follow-up laboratory session. On average the lecture would last around one hour, and then students would spend approximately two hours in the tutorial and laboratory session. The assessment criteria of student performance were divided into three main categories, namely design and fabrication of KML account for $30 \%$ of the total grade, design and fabrication of FLOS (40\%), and structural analysis including both manual and computer-based calculations (30\%). Before submission of each assignment, informal discussions between students and instructors were carried out in tutorial and exploratory learning hours, as the discussion and feedback between faculty and students was identified by Chickering and Gamson (1987) as one of recommended activities in undergraduate education.

\section{Evaluation of student feedback}

Upon the completion of the course, students from the two different courses were asked to provide feedback in the three categories, namely their overall evaluation of the course, their achievements of LOs, and expectations of the course to their future study and career. Before the feedback was analyzed and compared, students were surveyed of their previous performance in CE-relevant courses and motivation in structural analysis. This background information of students was collected to test the hypothesis that the students enrolled in both courses had consistent prior performance in CE study and similar motivation levels in practicing their structural modeling, analysis, and evaluation. A questionnaire survey-based approach was adopted to collect information regarding their background information and their feedback in terms of the three aforementioned categories. A follow-up comparative statistical analysis was conducted to investigate the consistencies and differences between WFA and CASA courses. 
The two-sample $t$-test, as one type of parametric methods, was adopted in this study to test the mean values between $W F A$ and $C A S A$ students for each Likert-scale item within the questionnaire. Parametric methods have been previously applied in the field of civil engineering in studies including Aksorn and Hadikusumo (2008), Meliá et al. (2008), and Tam (2009). Carifio and Perla (2008) and Norman (2010) displayed the robustness of parametric methods in data samples that were either small or not normally distributed. The sample sizes of 54 and 86 for $W F A$ and $C A S A$ students respectively were considered reasonable in this study. The two-sample t-test was based on the null hypothesis that students by Minitab, the statistical software, a $t$ value was computed for each item within the Likertscale questions and the corresponding $p$ value was obtained. Based on the $5 \%$ level of significance, a $p$ value lower than 0.05 would reject the null hypothesis and indicate that students from $W F A$ and $C A S A$ courses had different views on the given item.

\section{Student Work in Woodwork Fabrication and Analysis}

Students' workflow throughout this WFA course can be illustrated in Fig. 3, which consists of three major deliverables (i.e, woodwork drawing, fabricated products, and structural analysis) by applying different knowledge areas.

As shown in Fig.3, the work of each student was checked for its consistency between the woodwork drawings and fabricated products. For the structural modeling and analysis of FLOS, the structural model of each student was also checked for the consistency between the fabricated product and the computer-aided model. The student work is demonstrated below in terms of engineering graphics of KML and FLOS, fabrication of woodwork, computer-aided structural modeling and analysis.

\section{Engineering drawing}


242 Engineering drawings of KML and FLOS were completed by students prior to fabrication of woodwork. Fig.4 displays an example of engineering graphics for FLOS, including the top view, front view, side view, and the 3D perspective of the FLOS.

\section{Fabrication of woodwork}

Following the course delivery schedule displayed in Table 1, each student worked on the fabrication of KML and FLOS according to his or her own engineering drawing. Fig.5 and FLOS.

\section{Structural modeling and analysis}

Following the completion of woodwork products, students utilized the structural software SAP2000 to perform the simulation, analysis, and evaluation of the structure of the fabricated FLOS. Fig.6 demonstrates an example of structural analysis work.

Fig.6 demonstrates the structural analysis when the fabricated FLOS is under the load with an adult sitting on it. Besides the structural model, moment analysis, stress analysis, and deformation analysis, the same student work includes analysis related to axial load, torque, and shear force. Videos were produced by students to demonstrate the deformation of FLOS under the given load. Active learning and critical thinking were also found in structural analysis reports. For example, Fig.7 displays one student's FLOS woodwork in its tenon and mortise connection details where thin pieces of wood skins were added to fill the voids.

In the FLOS top surface displayed in Fig.7, a student found that the connection between tenon and mortise was loose. The student analyzed that the loose connection, which would not be found in pure computer-aided modeling and analysis, would cause the stress concentration along the mortise edges, and causing further issues in structural reliability. Therefore, the student performed extra work by adding thin wood pieces shown in Fig.7 to 
fill the voids in the tenon-mortise connection, and to ensure that the structural analysis is consistent with the fabricated model by avoiding putting extra stress on connections.

\section{Student Feedback}

270 In the spring of 2017, 59 and 91 students were enrolled in FWA and CASA courses, 271 respectively. Through the questionnaire survey conducted on students from both courses 272 during October 2017, 54 and 86 valid responses were received, respectively. Survey data of 273 student samples from $F W A$ and $C A S A$ courses were compared in terms of their prerequisites, overall course evaluation, perceptions of course effectiveness in achieving LOs, as well as expectations of the selected course to their further study and CE career.

\section{Prerequisites of students from both courses}

The hypothesis that students from both courses had consistent previous performance in CE relevant courses and similar motivation levels to studying structural analysis subjects were first tested using the two-tailed $t$-test. Four Likert-scale questions were asked to students, with 1 indicating their pervious performance was very poor or no motivation to study structural analysis subjects, 2 being below the average performance or not very interested in structural analysis, 3 meaning neutral, 4 referring to above the average or fairly interested in structural subjects, and 5 indicating excellent or highly motivated. Table 2 summarizes the test results.

All $p$ values above 0.05 indicate that both student samples had the highly consistent previous performance in relevant CE courses, as shown in Table 2. Both groups had also consistent levels of motivation to study structural analysis subjects. Similar prior performance and motivation of students in structural analysis-related curriculum would allow the followup comparison of student evaluation, perception, and expectations of the selected course, as the only variable in this pedagogical research is the structural course (i.e., either $F W A$ or $C A S A$ ) that students were enrolled in. 
Students were asked to evaluate the course that they were enrolled in using the numerical options from 1 to 5 , ranging from the least satisfied to the most satisfied. Percentages of students selecting each of the five given numerical options are displayed in Fig.8.

Around $72 \%$ of $F W A$ students surveyed provided positive responses to the course by and 5 denoting very positive impact. 

indicating students' perception between neutral and certain positive towards these three

described skills or knowledge, including engineering graphics, 3D modeling, and spatial reasoning. Although students from the CASA course, compared to their peers enrolled in $F W A$, perceived slightly more positive of the course in enhancing their skills in engineering graphics and 3D modeling, these differences were not significant as indicated by the $t$ and $p$ values. The five items in Table 3 were ranked according to their overall mean values, and the top two ranked items in both student samples were related to structural analysis, evaluation, and further understanding in structural forms. It can be found in Table 3 that students enrolled in both courses had generally consistent ranking of the five LOs.

Although the two top-ranked LOs in both student samples were all above the mean value at 4 , indicating that both courses were perceived with positive effects in enhancing students' skills in structural analysis and further understanding of structural forms, $p$ values close to 0.000 resulting from the comparison of the two student samples inferred that $F W A$ had far more positive impacts on students' structural skills compared to $C A S A$ as perceived by students.

\section{Course effects in future study and career}

Students were further asked about their longer-term expectations and how the course would affect their study of upper-year core courses within the CE program, their overall motivation and enthusiasm in their CE study, and the skills and knowledge required in their future careers. A Likert-scale question consisting of the three corresponding items listed in Table 4 was adapted to collect students' feedback. Students were given the numerical options to select among: 1 representing negative effects of their selected course to the given item in Table 4, 2 denoting little effect, 3 meaning not significantly positive effect, 4 indicating somewhat positive effect, and 5 meaning very positive effect. Students were also given an 
extra option 6 if they were unsure of the effect of the course to the given item. Excluding those who chose 6 , two-tailed $t$-tests were performed to compare the two student samples' survey data.

The overall mean values of each item in Table 4 were over or close to 4.000 , inferring that students had positive views of both courses' contribution to their upper-level core course study, motivation, and skills needed for their future career. All $p$ values higher than 0.05 conveyed the information that both courses were perceived by students with consistently positive effect in their future study and career. The rankings of the three items in Table 4 were the same for the two student samples, with the highest-ranked item being the course effect in their overall CE study.

\section{Discussion and Summary}

As part of the innovation in CE education at Wenzhou University, hands-on fabrication followed by structural modeling and analysis was incorporated in the $\mathrm{CE}$ curriculum. By incorporating Bloom (1956)'s Taxonomy Theory on learning domains and Anderson and Krathwohl (2001)'s revised taxonomy, students' learning activities described in Fig.1 were mapped in this newly created course entitled Woodwork Fabrication and Analysis (FWA). Students were guided to apply their prerequisites in engineering graphics and mechanics of materials in the drawing, fabrication, and structural analysis of the selected case studyChinese style FLOS. The traditional Computer-aided Structural Analysis (CASA) was maintained as the other semi-optional course to achieve consistent learning outcomes (LOs). Students enrolled in $C A S A$ were treated as the control group to study the effects of the $F W A$ course in sophomore CE students' learning.

This pedagogical study was divided into two major sections, namely demonstration of student work in FWA course, and statistical comparison of the two student samples from FWA and CASA courses. Following the workflow described in Fig.3, student work in FWA 
course was demonstrated with engineering drawings, woodwork fabrication, and application of mechanics of materials to structural modeling and analysis. Active learning and critical thinking targeted in engineering education proposed by Jin et al. (2018) were demonstrated with student sample work in FWA.

Following the completion of student work in these two semi-optional courses, statistical tests were performed to compare the two student samples' overall evaluation of their selected course, perceptions on enhancements of key LOs, as well as the expectations of the selected course to their future study and career. Before the statistical comparison was conducted to evaluate the three major aforementioned categories, the hypothesis that both student samples had consistent previous academic performance and similar motivation levels in studying structural subjects were validated. Therefore, the variable within the two student samples would be in the FWA course which incorporated hands-on experience of tool usage for woodwork fabrication. In comparison, students enrolled in CASA adopted the traditional residential building for structural modeling and analysis. Though both student groups had consistent views on the course's enhancement on their engineering graphics, 3D modeling skill, and spatial reasoning capability, students enrolled in $F W A$ were found with significantly higher overall satisfaction of FWA and more positive perceptions of it in enhancing their skills in structural analysis and further understanding on local force distribution. It could be inferred that integrated teaching and learning activities incorporating hands-on fabrication actually led to more significant enhancement in further structural analysis and evaluation, beyond the hands-on skill itself.

Despite the more positive overall evaluation and perceptions in enhancing their structural analysis skills, students from both courses had generally consistent and positive evaluation of the selected course in meeting their expectations and impacting their follow-up studies. Both student samples had also highly positive views on the course effects in their upper-year 
studies in CE core courses, motivation and enthusiasm in CE field, as well as skills and knowledge needed in their future professional career. These consistent views for students from both courses inferred that traditional structural analysis course in this pedagogical study still had its own merit, especially in influencing students' follow-up learning and practice. Traditional courses may also have its own advantages especially considering the constraints of laboratory resources needed in hands-on fabrication-involved alternative courses. As mentioned by Mackechnie and Buchanan (2012), universities are under pressure to cut the expense of laboratory education for engineering students.

The traditional undergraduate curriculum of CE programs in many Chinese universities still focuses on aligning lower level domains (i.e., remembering and understanding) defined in Bloom's Taxonomy Theory and Anderson and Krathwohl (2001) in lower years' teaching, and then starts aligning applying, analyzing, and other higher domain levels in upper years of their CE programs. Throughout the delivery of this FWA course, researchers believed that multiple alignment levels beyond remembering and understanding could be incorporated in early years' undergraduate CE programs. According to Ríos et al. (2010) and Soria et al. (2013), certain teaching methodology adopted in one course or program could be extended to other programs or for other educators within the same field to incorporate. Similarly, the developed integrated pedagogical approach in this FWA course adopting various learning activities targeting multiple skills (e.g., hands-on fabrication and computer modeling) could also be applied to other CE programs and employed by a wide range of educators in the CE community. The initial findings from this pedagogical research would provide insights for further promoting the hands-on learning to a wider student population covering multiple disciplines including architecture, $\mathrm{CE}$, and other engineering subjects. Faculties in the CE program of Wenzhou University would address the issue of maintaining the education resources in this WFA course meanwhile increasing the multi-disciplinary feature as 
suggested by Dederichs et al. (2011), Saleh and Pendley (2012), Clevenger et al., (2017),

Sharma et al. (2017), and Wirth et al. (2017) for future course delivery.

\section{Conclusions}

This pedagogical study introduced the new course of Woodwork Fabrication and

424

Analysis at Wenzhou University. It was designed and delivered through integrated teaching objectives and multiple learning activities (e.g., hands-on fabrication of woodwork) which were mapped against Bloom's Taxonomy Theory and its updated cognitive domains. As an alternative to the conventional course entitled Computer-aided Structural Analysis, this WFA course was designed to achieve consistent learning outcomes in terms of engineering graphics, 3D modeling, spatial reasoning, and further learning in structural analysis. This WFA course demonstrated second year CE students' work in applying engineering graphics, hands-on woodwork fabrication, and software modeling for structural analysis. Students were motivated with their critical thinking and active learning. Students' feedback of the postcourse-delivery from both semi-optional courses was collected and compared focusing on their overall satisfaction, their perceptions of the course's effectiveness in enhancing CErelated skills, and their longer-term expectations of their selected course on their future study and career. Based on the fact that students enrolled in both courses had the consistent previous performance and similar motivations towards structural analysis, the following findings generated from the comparative study could serve as references for other higher education institutions in CE field:

- The skills and knowledge that students gained through the integrated teaching and learning activities could generate more positive feedback in overall satisfaction of the course, as well as more positive views on the course effectiveness;

- Integrated teaching and learning (e.g., hands-on fabrication) could lead to more positive perceptions on the course's effectiveness in improving their structural analysis skills. It 
was indicated that hands-on learning activities could not only improve students' skills in fabrication itself, but also assist in developing students' further skills described in the learning outcomes (i.e., structural analysis and evaluation);

- Multiple levels of cognitive domain according to Bloom's Taxonomy Theory can be applied in the early of CE education to achieve multiple learning outcomes corresponding to remembering, comprehension, applying, analysis, and evaluation. CE institutions do

\section{Data Availability Statement}


by request.

\section{Acknowledgement}

The authors would like to acknowledge the support from Department of Education of Zhejiang Province (Contract No.: jg20160260) in conducting this pedagogical study. The authors would also like to acknowledge the support from the Writing Retreat Fund provided by University of Brighton.

\section{References}

Aksorn, T., and Hadikusumo, B.H.W. (2008). "Critical success factors influencing safety program performance in Thai construction projects.” Safety Sci., 46 (4), 709-727.

Amekudzi, A.A., Li, L., and Meyer, M. (2010). "Cultivating research and information skills in civil engineering undergraduate students."J. Prof. Issues Eng. Educ. Pract., 136(1), $24-29$.

Anderson, L.W., and Krathwohl, D. R. (2001). "A taxonomy for learning, teaching, and assessing: a revision of Bloom's taxonomy of educational objectives." New York, Longman.

Beiler, M.R.O., and Evans, J. (2015). "Teaching sustainability topics to attract and inspire the next generation of civil engineers." J. Prof. Issues Eng. Educ. Pract., 141 (2), C5014001.

Bloom, B.S. (1956). "Taxonomy of educational objectives, the classification of educational goals - Handbook I: cognitive domain.” New York, McKay. 16.

Burbach, M. E., Matkin, G. S. and Fritz, S. M. (2004). "Teaching critical thinking in an introductory leadership course utilizing active learning strategies: A confirmatory study." Coll. Stud. J., 38(3), 482.

Bussey, M., Song, M.M., and Hsieh, S.H. (2017). Anticipatory imagination as a tool for rethinking engineering education. J. Prof. Issues Eng. Educ. Pract., 143 (4), 02517004.

Carifio, L., and Perla, R. (2008). "Resolving the 50 year debate around using and misusing Likert scales." Med. Educ., 42(12), 1150-1152.

Cerato, A.B., Taghavi, A., Muraleetharan, K.K., and Miller, G.A. (2012). "Educational module to demonstrate the seismic behavior of piles in improved and unimproved soft soils."J. Prof. Issues Eng. Educ. Pract., 138 (4), 274-282.

Chacón, R., and Oller,S. (2017). "Designing experiments using digital fabrication in structural dynamics.” J. Prof. Issues Eng. Educ. Pract, 143 (3), 05016011. 
Chickering, A.W. and Gamson, Z.F. (1987), "Seven principles for good practice in undergraduate education. American Association for Higher Education \& Accreditation Bulletin." March, 39 (7), pp. 3-7. Available from www.aahea.org/bulletins/articles/sevenprinciples1987.htm [Accessed 18 November 2017]

China Education On-Line. (2014)."Ten undergraduate degrees with highest numbers of graduates: Civil Engineering."Available via http://www.eol.cn/gaozhong_news 11021/20141022/t20141022 1192872.shtml, accessed on October 27 2017.

Clevenger, C.M., Brothers, H., Abdallah, M., and Wolf, K. (2017). "Initial assessment of a newly launched interdisciplinary construction engineering management graduate program."J. Prof. Issues Eng. Educ. Pract, 143 (3), 04017001.

Computers and Structures, Inc. (2017). "SAP2000 v19: integrated software for structural

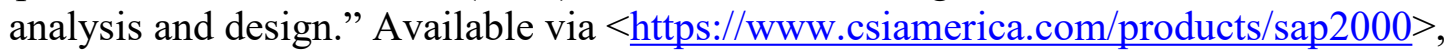
assessed on February $3^{\text {rd }}, 2017$.

Dancz, C.L.A., Bilec, M.M., and Landdis, A.E. (2018). "Active experiential sustainable engineering module for engineering education.”J. Prof. Issues Eng. Educ. Pract., 144 (1), 04017011 .

DataUSA (2015). "Civil Engineering: stem major.”available via https://datausa.io/profile/cip/1408/, accessed on October $27^{\text {th, }} 2017$.

Gadhamshetty, V., Shrestha, N., and Kilduff, J.E. (2016). "Project-based introduction to an engineering design course incorporating microbial fuel cells as a renewable energy technology." J. Prof. Issues Eng. Educ. Pract., 142 (3), 05016001.

Jackson, H.V., and Tarhini, K.M.(2016). "Progressive integration of design process into civil engineering curriculum.”J. Prof. Issues Eng. Educ. Pract., 142 (3), 05015006.

Jainudin, N.A., Francis, L., Tawie, R., and Matarul, J. (2015). "Competency of civil engineering students undergone industrial training: supervisors' perspectives." Procedia Soc. Behav. Sci., 167, 245-249.

Jin, R., Yang, T., Piroozfar, P., Kang, B.G, Wanatowski, D., Hancock, C.M., and Tang, L. (2018). "Project-based pedagogy in interdisciplinary building design adopting BIM." Eng. Construct. Architect. Manag., In Press.

Jin, R., Tang, L., Hancock, C.M., and Allan, L. (2016). "BIM-based multidisciplinary building design practice-a case study." HealthyHousing2016: Proceedings of the 7th International Conference on Energy and Environment of Residential Buildings, November 2016, Brisbane, Australia.

Kubečková, D. (2014). "Lifelong learning as a part of training in the field of civil engineering."Procedia Soc. Behav. Sci., 141, 623-627. 
Lewis, A.M., Vasquez, R.V., Clevenger, C., and Shealy, T. (2015). "BIM energy modeling: case study of a teaching module for sustainable design and construction courses." J. Prof. Issues Eng. Educ. Pract., 141(2), C5014005.

Lucas, J. (2016). "Seeking a balance between student and industry expectations for technology exposure in construction education." J. Prof. Issues Eng. Educ. Pract., 143(3), 05016013 .

Mackechnie, J.R., and Buchanan, A.H. (2012). "Creative laboratory model for large undergraduate engineering classes.” J. Prof. Issues Eng. Educ. Pract., 138 (1), 55-61.

Meliá, J. L., Mearns, K., Silva, S. A., and Lima, M. L. (2008). "Safety climate responses and the perceived risk of accidents in the construction industry." Safety Sci., 46 (6), 949-958.

Meyers, C. and Jones, T. B. (1993). "Promoting active learning: strategies for the college classroom.” Jossey-Bass Inc., Publishers, 350 Sansome Street, San Francisco, CA 94104.

Minitab [Computer software]. Minitab, Inc., State College, PA.

Mosalam, K.M., Hube, M.A., Takhirov, S.M., and Günay, S. (2013). "Teaching innovation through hands-on-experience case studies combined with hybrid simulation." J. Prof. Issues Eng. Educ. Pract., 139(3), 177-186.

Mostafavi, A.M., Huff, J.L., Abraham, D.M., Oakes, W.C., and Zoltowski, C.B. (2016). "Integrating service, learning, and professional practice: toward the vision for civil engineering in 2025.” J. Prof. Issues Eng. Educ. Pract., 142(3), B4013001.

Norman, G. (2010). "Likert scales, levels of measurement and the 'laws' of statistics." $A d v$. Health. Sci. Edu., 15(5), 625-632.

Phillips, A.T.M. (2017). "Engineering education, research, and design: breaking in and out of liminal space."J. Prof. Issues Eng. Educ. Pract., 143(4), 02517002.

Rios, I.L., Cazorla, A., Díaz-Puente, J. M., and Yagüe, J. L. (2010). “Project-based learning in engineering higher education: two decades of teaching competences in real environments."Procedia Soc. Behav. Sci., 2(2), 1368-1378.

Sacks, R., and Barak, R. (2010). "Teaching Building Information Modeling as an integral part of freshman year civil engineering education." J. Prof. Issues Eng. Educ. Pract., 136(1), 30-38.

Saleh, J.H., and Pendley, C.C. (2012). "Form learning from accidents to teaching about accident causation and prevention: multidisciplinary education and safety literacy for all engineering students.” Reliab. Eng. Syst. Safe., 99, 105-113.

Salmisto, A., Postareff, L., and Nokelainen, P. (2017). "Relationships among civil engineering students' approaches to learning, perceptions of the teaching-learning environment, and study success." J. Prof. Issues Eng. Educ. Pract., 143(4), 04017010. 
10 41 42

Sánchez, G.F., and Millán, M. Á. (2013). "Structural analysis education: learning by handson projects and calculating structures." J. Prof. Issues Eng. Educ. Pract., 139(3), 244247.

Sharma, B., Steward, Ong, S.K., and Miguez, F.E. (2017). "Evaluation of teaching approach and student learning in a multidisciplinary sustainable engineering course." J. Clean. Prod., 4032-4040.

Soria, B.R., Bella, J.M.P., Hernández, J.D., Suñén, E.C., and Díaz J.J.C. (2013). “Education for sustainable development: methodology and application within a construction course."J. Prof. Issues Eng. Educ. Pract., 139(1), 72-79.

Tam, V.W.Y. (2009). "Comparing the implementation of concrete recycling in the Australian and Japanese construction industries." J. Clean. Prod., 17(7), 688-702.

Tang, L., Jin, R., and Fang, K. (2015). "Launching the innovative BIM module for the architecture and built environment programme in China," in BIM 2015 First International Conference on Building Information Modelling (BIM) in Design, Construction and Operations, WIT Transactions on The Built Environment, 149 (2015), 145-156.

Walker, S. E. (2003). “Active learning strategies to promote critical thinking.” J. Athl. Train., 38(3), 263.

Wirth, X., Jiang, N.J., Silva, T., Vecchina, G.D., and Evans, J., Romero, R., and Bhatia, S.K. (2017). "Undergraduate geotechnical engineering education of the $21^{\text {st }}$ century." J. Prof. Issues Eng. Educ. Pract., 143(3), 02516002.

Youngblood, N., and Beitz, J. M. (2001). "Developing critical thinking with active learning strategies." Nurse Educ., 26(1), 39-42. 
650

658

659

660

665

666

667

668

669

670

671

672

673

674

675

676

677

678

Table 1. Table 1. The WFA Course structure of integrated woodwork design, fabrication, and structural analysis

Table 2. Test results of student prerequisites in the two courses

Table 3. Test results of student prerequisites in achieving LOs

Table 4. Expectations of the selected course in CE study and professional career

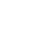

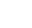

0

(1)

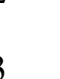

64


Table 1. The WFA Course structure of integrated woodwork design, fabrication, and

680 structural analysis

\begin{tabular}{|c|c|c|c|c|c|}
\hline \multirow[t]{2}{*}{ Module } & \multirow[t]{2}{*}{ Teaching and learning activities } & \multicolumn{4}{|c|}{ Study hours } \\
\hline & & Lecture & Tutorial & $\begin{array}{l}\text { Exploratory } \\
\text { learning }\end{array}$ & $\begin{array}{l}\text { Assignment } \\
\text { (approximate) }\end{array}$ \\
\hline Introduction & $\begin{array}{l}\text { Course description including } \\
\text { prerequisites, teaching contents, } \\
\text { learning outcomes, and laboratory } \\
\text { orientation }\end{array}$ & 4 & 2 & 0 & 1 \\
\hline $\begin{array}{l}\text { Woodwork } \\
\text { design }\end{array}$ & $\begin{array}{l}\text { Learning the basic design } \\
\text { software- Sketchup; presenting } \\
\text { the Chinese traditional } \\
\text { woodwork; showing the structure } \\
\text { of the KML and FLOS with } \\
\text { Three-View of KML and FLOS }\end{array}$ & 4 & 6 & 0 & 6 \\
\hline $\begin{array}{l}\text { Hands-on } \\
\text { work of } \\
\text { woodwork }\end{array}$ & $\begin{array}{l}\text { Learning the basics of the } \\
\text { woodwork from both tutorial } \\
\text { videos and handouts; tutorial for } \\
\text { utilizing manual and electrical } \\
\text { tools for woodwork fabrication } \\
\text { provided by a senior woodworker } \\
\text { and two tutors; students' } \\
\text { completion of KML and FLOS } \\
\text { fabrication in workshops }\end{array}$ & 10 & 12 & 10 & 30 \\
\hline $\begin{array}{l}\text { Structural } \\
\text { analysis and } \\
\text { simulation }\end{array}$ & $\begin{array}{l}\text { Learning the basics of the } \\
\text { structural analysis software; } \\
\text { simulating FLOS in the different } \\
\text { loading patterns; assessing the } \\
\text { stress-strain contour and its } \\
\text { localization; evaluating the effect } \\
\text { of the leg angle on the structure's } \\
\text { response; Completing the } \\
\text { structural analysis and presenting } \\
\text { the report }\end{array}$ & 7 & 9 & 9 & 10 \\
\hline & Total hours & 25 & 29 & 19 & 47 \\
\hline
\end{tabular}


Table 2. Test results of student prerequisites in the two courses

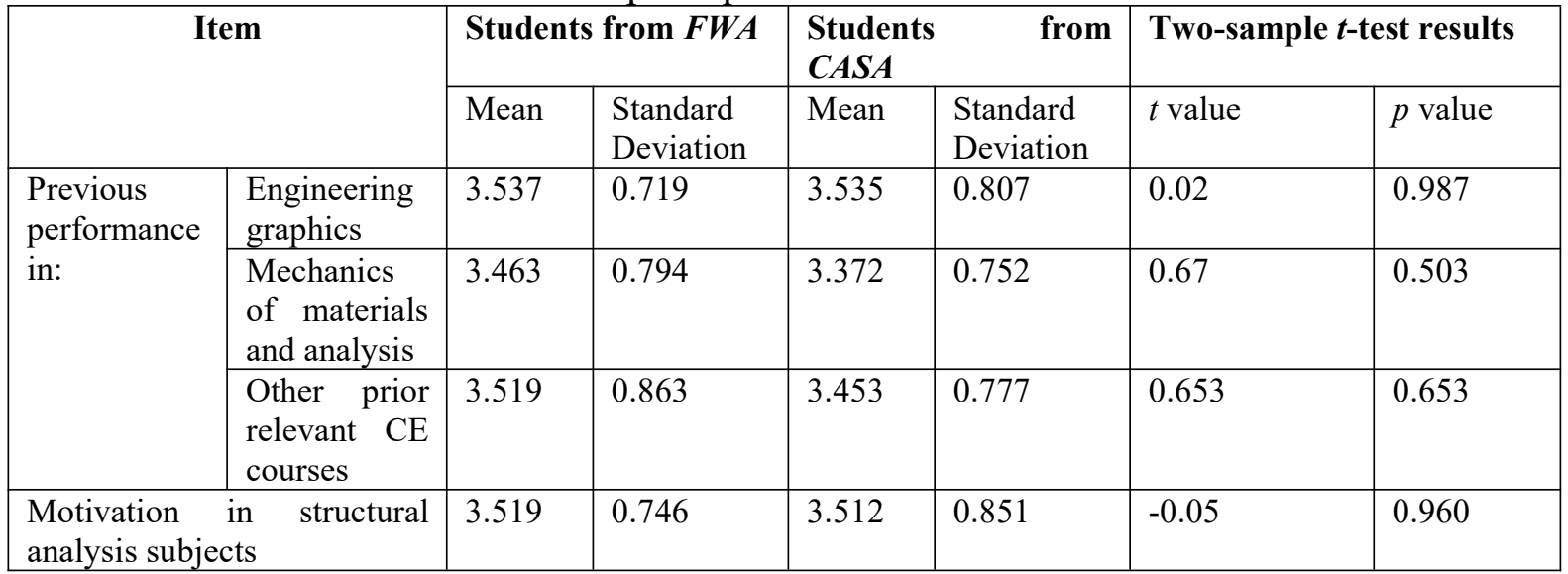

694

695

696

697

698

699

700

701

702

703

704

705

706

707

708

709

710

711

712

713

714

715

716 
Table 3. Test results of student prerequisites in achieving LOs

\begin{tabular}{|c|c|c|c|c|c|c|c|c|}
\hline \multirow[t]{2}{*}{ LO Item } & \multicolumn{3}{|c|}{ Students from $F W A$} & \multicolumn{3}{|c|}{ Students from $C A S A$} & \multicolumn{2}{|c|}{$\begin{array}{l}\text { Two-sample } t \text {-test } \\
\text { results }\end{array}$} \\
\hline & Mean & $\begin{array}{l}\text { Standard } \\
\text { Deviation }\end{array}$ & Rank & Mean & $\begin{array}{l}\text { Standard } \\
\text { Deviation }\end{array}$ & Rank & $t$ value & $p$ value \\
\hline $\begin{array}{l}\text { 1. Engineering } \\
\text { graphics skill }\end{array}$ & 3.833 & 0.694 & 4 & 3.895 & 0.812 & 4 & -0.48 & 0.631 \\
\hline 2. 3D modeling skill & 3.759 & 0.725 & 5 & 3.930 & 0.716 & 3 & -1.36 & 0.175 \\
\hline $\begin{array}{l}\text { 3. Spatial reasoning } \\
\text { skill }\end{array}$ & 3.889 & 0.718 & 3 & 3.837 & 0.765 & 5 & 0.40 & 0.687 \\
\hline $\begin{array}{l}\text { 4. Structural analysis } \\
\text { in terms of } \\
\text { interpreting } \\
\text { simulation results and } \\
\text { evaluating structural } \\
\text { optimization }\end{array}$ & 4.796 & 0.451 & 1 & 4.395 & 0.830 & 1 & 3.70 & $0.000 *$ \\
\hline $\begin{array}{l}\text { 5. Understanding on } \\
\text { local force distribution } \\
\text { in various parts of } \\
\text { structural forms }\end{array}$ & 4.648 & 0.482 & 2 & 4.163 & 0.893 & 2 & 4.17 & $0.000 *$ \\
\hline
\end{tabular}

*: a $p$ value lower than 0.05 indicates significant differences of students' perceptions on achievement of the given LO item. 
Table 4. Expectations of the selected course in CE study and professional career Item

\begin{tabular}{|c|c|}
\hline Students from $F W A$ & Students from $C A S A$ \\
\hline
\end{tabular}
results

Mean Standard Rank Mean Standard Rank $t$ value $p$ value

\begin{tabular}{|c|c|c|c|c|c|c|c|c|}
\hline $\begin{array}{l}\text { 1. Upper-year studies } \\
\text { of core courses in } \mathrm{CE}\end{array}$ & 3.980 & 0.721 & 3 & 3.924 & 0.797 & 3 & 0.41 & 0.685 \\
\hline $\begin{array}{l}\text { 2. Motivation and } \\
\text { enthusiasm in overall } \\
\text { CE study }\end{array}$ & 4.137 & 0.664 & 1 & 4.013 & 0.803 & 1 & 0.97 & 0.336 \\
\hline $\begin{array}{l}\text { 3. Skills and } \\
\text { knowledge needed for } \\
\text { future career }\end{array}$ & 4.040 & 0.755 & 2 & 3.949 & 0.788 & 2 & 0.66 & 0.513 \\
\hline
\end{tabular}

*: a $p$ value lower than 0.05 indicates significant differences of students' perceptions on achievement of the given LO item. 
Fig.1. WFA Course design by mapping teaching and learning activities into Bloom's Taxonomy Theory and the theory updated by Anderson and Krathwohl (2001).

Fig.2. Demonstrations of Kong-Ming lock and a four-leg octagonal stool Fig.2a). Kong-Ming lock Fig.2b). Four-legged octagonal stool

Fig.3. Student workflow within the course

Fig. 4. An example of student work applying engineering graphics to FLOS

Fig.5. Students' fabrication of woodwork

Fig.5a). Students working on hands-on fabrication

Fig.5b). An example of students completed woodwork products (i.e., FLOS and KML)

Fig.6. Structural analysis of woodwork

Fig.6a). Structural model of FLOS

Fig.6b). Moment analysis

Fig.6c). Stress analysis

Fig.6d). Deformation analysis

Fig.7. Tenon and mortise in the FLOS top plate surface

Fig.8. Survey results of course satisfaction 


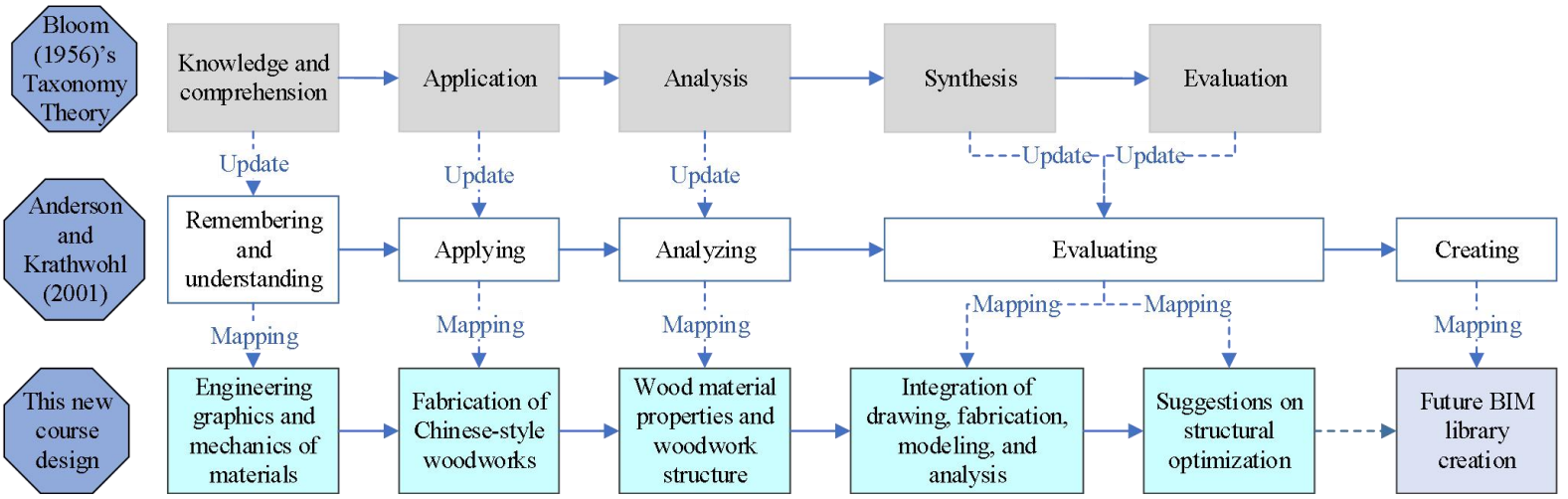

Fig.1. WFA Course design by mapping teaching and learning activities into Bloom's 791 Taxonomy Theory and the theory updated by Anderson and Krathwohl (2001). 


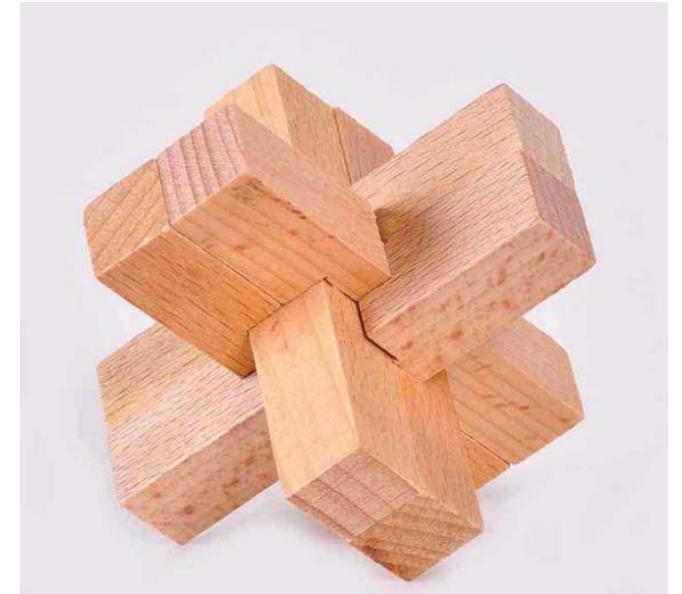

a) Kong-Ming lock

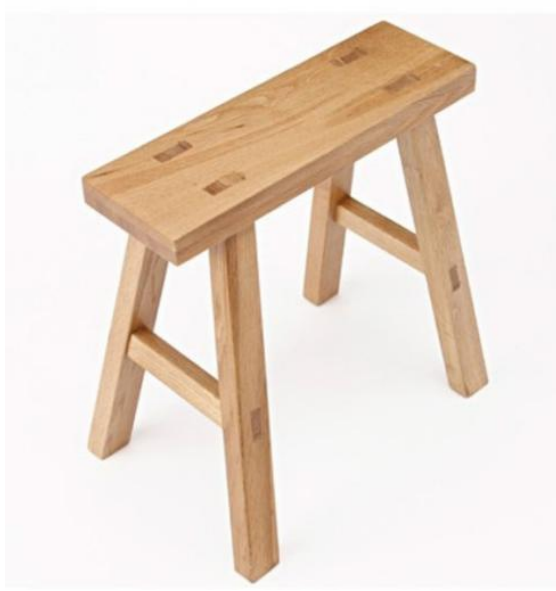

b) Four-legged octagonal stool

811 Fig.2. Demonstrations of Kong-Ming lock and a four-leg octagonal stool 


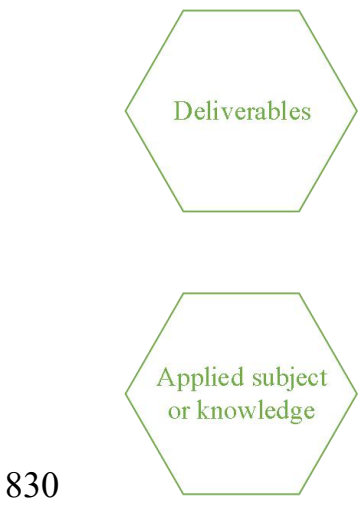



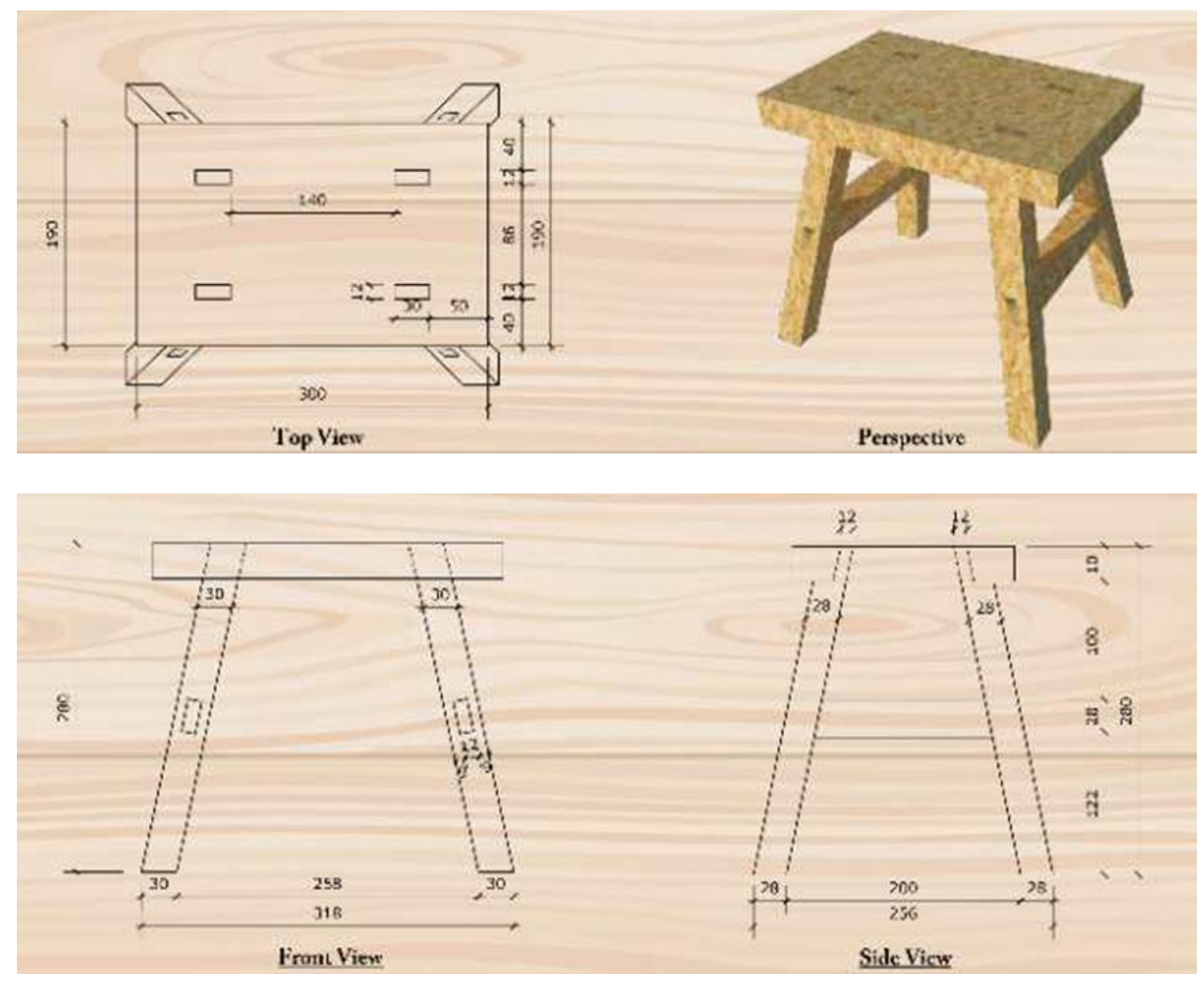


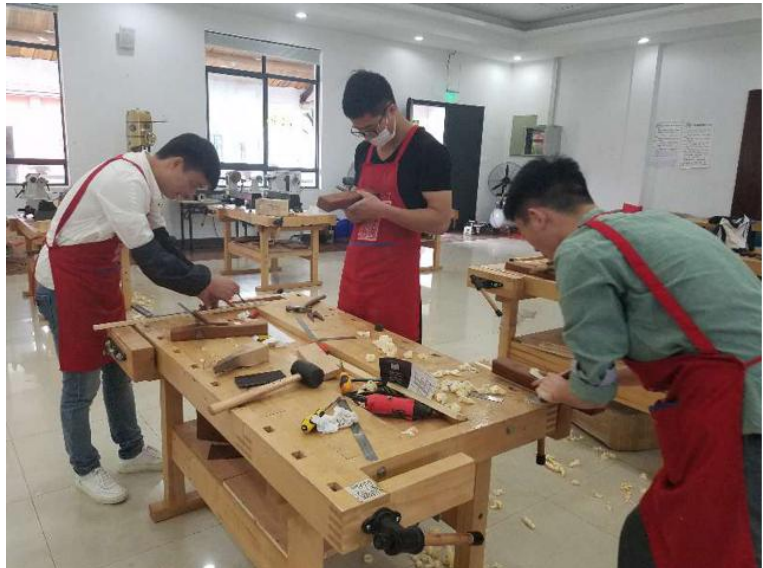

a) Students working on hands-on fabrication

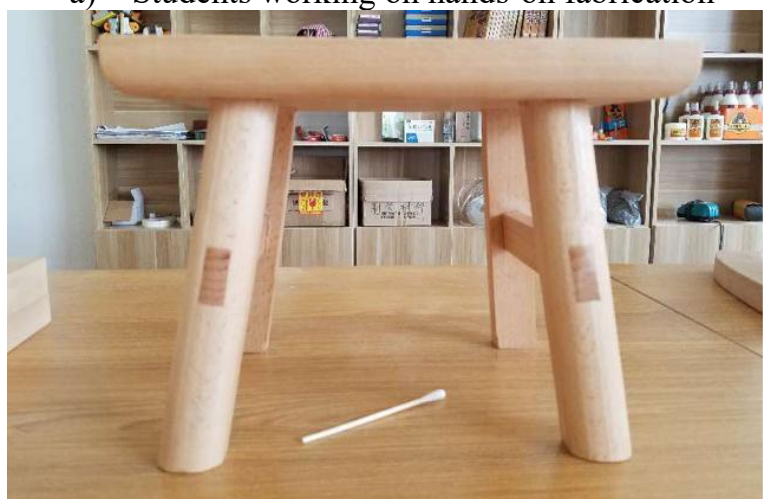

b) An example of students completed woodwork products (i.e., FLOS and KML) 


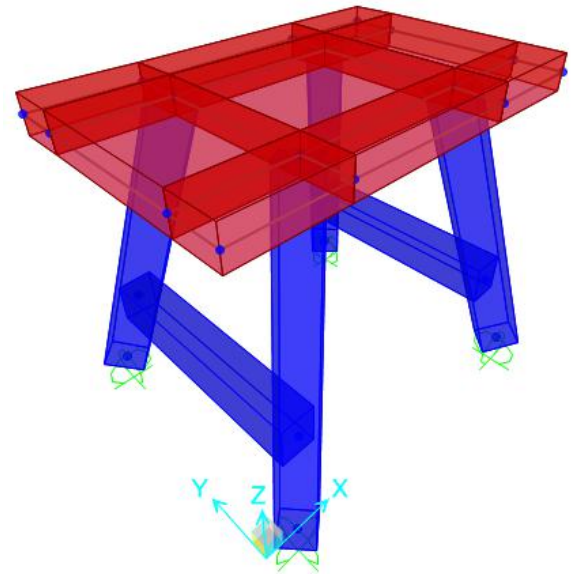

a) Structural model of FLOS

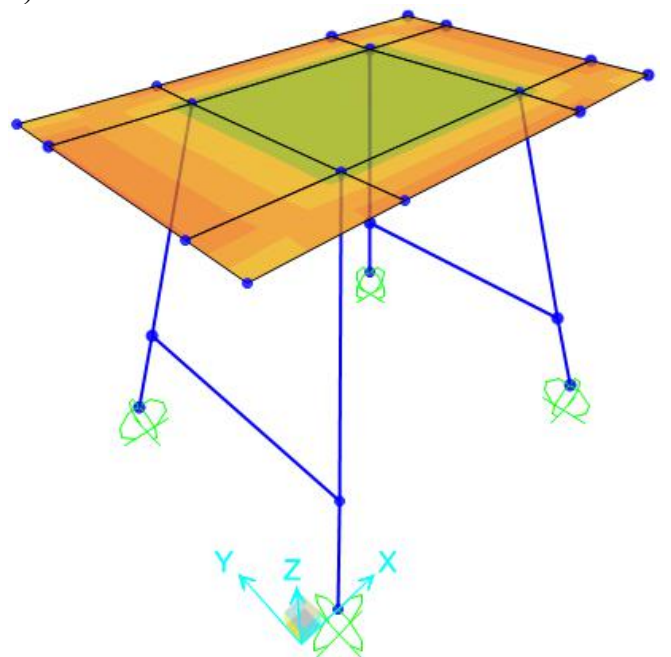

c) Stress analysis

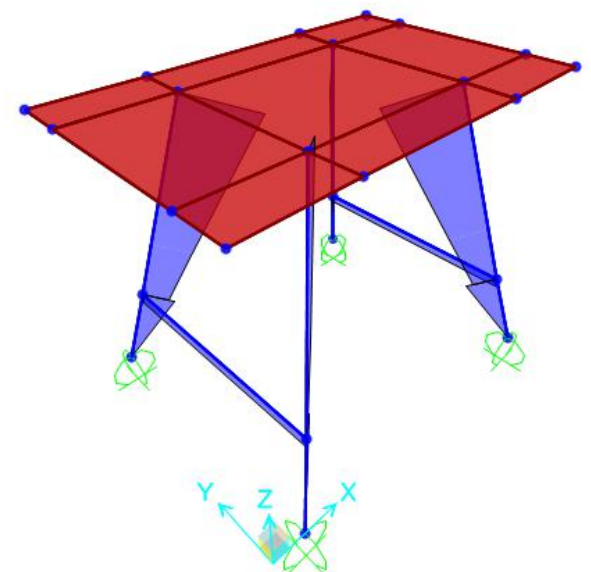

b) Moment analysis

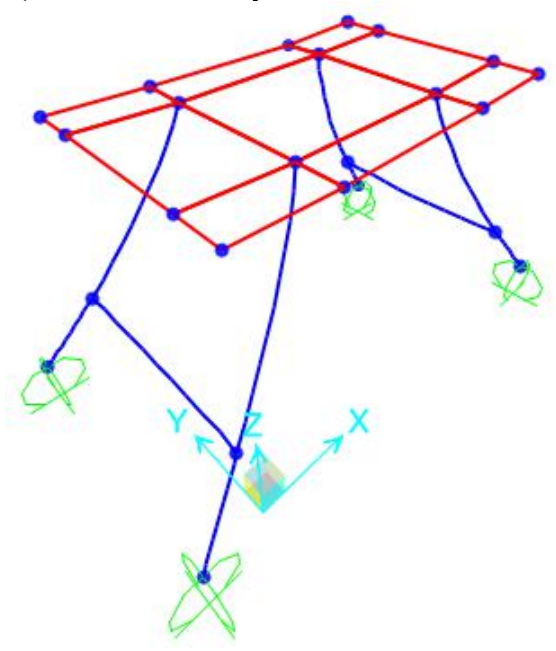

d) Deformation analysis

Fig.6. Structural analysis of woodwork 


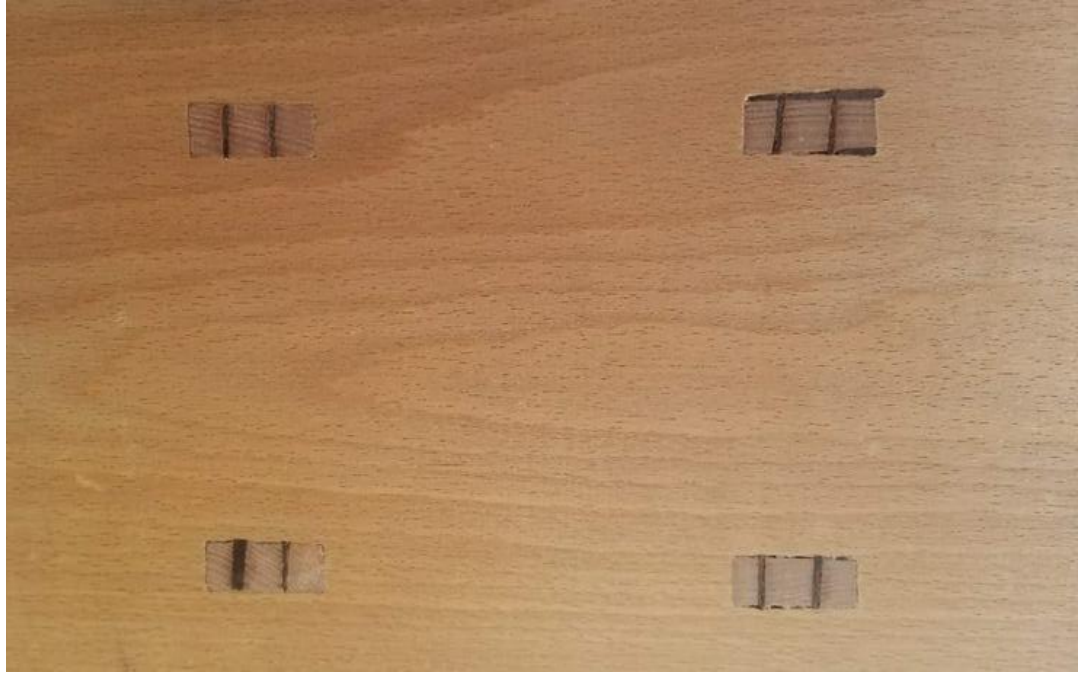

892

Fig.7. Tenon and mortise in the FLOS top plate surface

895

896

897

898

899

900

901

902

903

904

905

906

907

908 


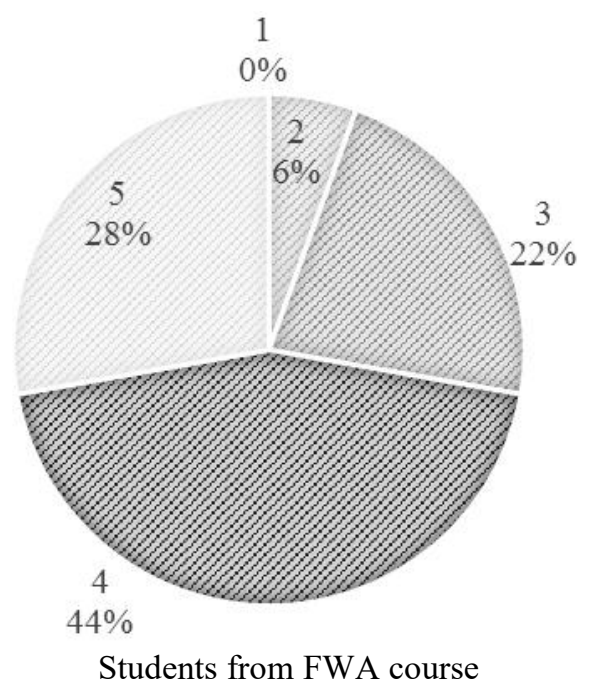

Students from FWA course

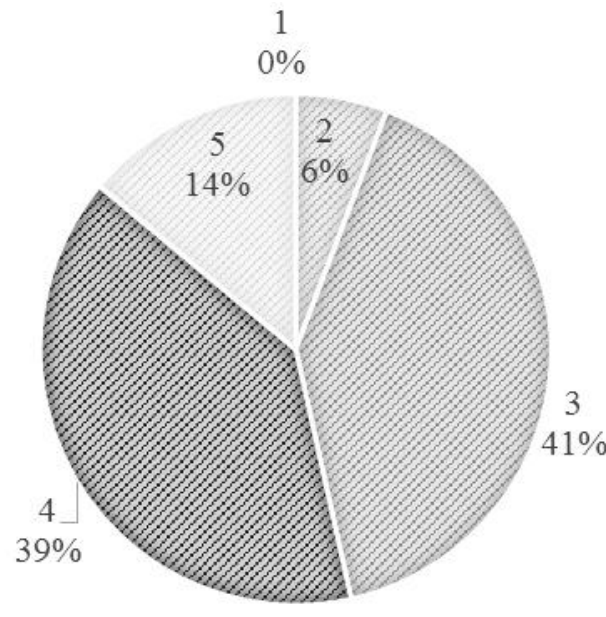

Students from CASA course
910

911

912
Fig.8. Survey results of course satisfaction 